\title{
Petróleo e porto no norte do estado do Rio de Janeiro, Brasil
}

José-Luis Cruz. Universidade Candido Mendes, Campos dos Goytacazes, Brasil. Denise Terra. Universidade Estadual do Norte Fluminense Darcy Ribeiro, Campos dos Goytacazes, Brasil.

RESUmo | Este artigo analisa a dinâmica econômica recente do estado do Rio de Janeiro/Brasil, sob a perspectiva do padrão de crescimento econômico brasileiro, focando no processo em curso no norte do estado. Serão abordados os impactos socioespaciais dos grandes projetos de infraestrutura e produção, vinculados a esse padrão, bem como serão identificados os conflitos decorrentes. Busca-se contribuir para as reflexôes acerca das tendências e implicaçóes da participação das economias periféricas na nova Divisão Internacional do Trabalho, para se pensar a amplitude e profundidade da dinâmica atual de domínio do capital financeiro especulativo e da crise mundial vinculada estreitamente à crise capitalista. $\mathrm{O}$ artigo destacará o Complexo de Exploração e Produção off shore de Petróleo e Gás da Bacia de Campos, e o Complexo Industrial e Portuário do Açu bem como apontará quatro casos de grupos sociais atingidos pelos impactos desestruturantes desses grandes projetos de investimento, que se espraiam na periferia capitalista.

PALAVRas-CHaVe | desenvolvimento regional e local, reestruturação econômica, conflito social.

ABSTRACT | This article analyzes the recent economic dynamics of the state of Rio de Janeiro / Brazil, from the perspective of the pattern of Brazilian economic growth, focusing on the current process in the north of the State. The article addresses the socio-spatial impacts of the major infrastructure and production projects linked to this pattern, as well as the resulting conflicts. This work seeks to contribute to the reflections on the trends and implications of the participation of the peripheral economies in the new International Division of Labor, in order to reflect about the breadth and depth of the current dynamics of speculative financial capital and the global crisis closely linked to the capitalist crisis. The article will highlight the Offshore Oil and Gas Exploration and Production Complex of the Campos Basin and the Açu Industrial and Port Complex as well as four cases of social groups affected by the destructive impacts of these large investment projects, which spread to the capitalist periphery.

KEYWORDS | regional and local development, economic restructuring, social conflict.

Recebido em 19 de outubro de 2018, aprovado em 23 de maio de 2019.

E-mails: J.-L. Cruz, joseluisvianna@uol.com.br | D. Terra, deniseterra@gmail.com 


\section{Introduçáo}

O Estado do Rio de Janeiro (ERJ) vem, desde meados da década de 1990, revertendo um longo período de estagnação e declínio econômico, ocorridos da década de 1970 à de 1990 (Oliveira, 2008, p. 47), quando chegou a perder, em alguns momentos, a segunda posição no ranking dos estados mais ricos do país - em termos do PIB para o Estado de Minas Gerais. A transferência da capital do país do Rio de Janeiro para Brasília, em 1961, e a crise econômica dos anos 1980-1990, produziram um esvaziamento do parque industrial e o esgotamento da agricultura e da agroindústria tradicionais, punidas por seu baixo nível de modernização. A economia fluminense manteve a sua concentração na capital, Rio de Janeiro, e na Região Metropolitana (RMRJ). O parque industrial consistia, principalmente, na indústria de base e de semi-industrializados, assim como de bens não duráveis.

No entanto, ao final dos anos 1970 o ERJ iniciou a produção offshore de petróleo \& gás, que veio a representar quase $90 \%$ da produção nacional de óleo, até meados da primeira década do século xxI. O estado também possui um dos três maiores complexos petroquímicos do país, na produção de petroquímicos básicos. Esse complexo foi criado em 1961 e a ele foi agregado um importante polo gás-químico, e uma destacada indústria naval. Esta teve um período de decadência entre a década de 80 até 2007, quando foi recuperada por uma política federal de encomendas para a indústria petrolífera. Todavia, a indústria naval encontra-se em crise novamente, desde 2015, dados os problemas enfrentados pela Petrobras, sua maior cliente, e devido também à retração do mercado internacional de petróleo. A Petrobras, petrolífera estatal, detinha o monopólio da exploração e produção, até 1997, quando foi extinto por lei federal. A crise se deve, em parte, ao represamento dos preços domésticos dos combustíveis, desde 2011, inviabilizando o plano de investimentos 2012-2016, bem como às investigaçôes de corrupção na empresa, que afetaram seu programa de investimentos. A partir de 2008, iniciou-se a construção do que seria o maior polo petroquímico do Brasil, o Complexo Petroquímico do Rio de Janeiro (Comperj), na RMrJ (Oliveira, 2008, p. 48). São eles os principais componentes da cadeia da indústria petrolífera no ERJ.

A extração petrolífera gerou rendas de elevadíssima monta para o Estado e para uma dezena de municípios privilegiados, particularmente a partir de 1998. Mais recentemente, a partir da segunda metade da década de 2000 , um conjunto de Grandes Investimentos, espalhados por parte do seu território - principalmente no interior - foram postos em marcha, provocando profundas alteraçóes nas configuraçôes urbanas e urbano-regionais da dinâmica espacial estadual. Os Grandes Investimentos, tratados aqui sob a sigla GI, são investimentos públicos e privados de grande porte, em termos de capital, da área e do peso, em valores absolutos e relativos, no segmento a que estáo ligados, e da capacidade de impacto no ambiente natural e construído. Esses investimentos podem ser tipificados como: i) de infraestrutura urbana: habitação e saneamento, principalmente; ii) de infraestrutura econômica: rodovias, ferrovias, portos e terminais portuários, e aeroportos, principalmente; iii) industriais: complexo de extração e produção de petróleo e gás (E\&P); complexo petroquímico e gás-químico; complexo metal-mecânico e siderúrgico; complexo 
automotivo; e iv) turísticos: infraestrutura e equipamentos urbanos voltados para grandes eventos esportivos internacionais e entretenimento, na capital, Rio de Janeiro. Os investimentos dos três primeiros grupos se dão majoritariamente no interior, fora do município da capital, e incluem municípios da RMRJ (Cruz, 2016).

Esses investimentos são viabilizados, em sua maior parte, por recursos federais, isoladamente ou em parcerias com o capital privado, e se inscrevem na estratégia de inserção do Brasil na economia internacional. Essa inserção se dá: pela consolidação da produção agrícola e agroindustrial para exportação, com uma pauta variada; pelo fortalecimento da tradicional produção mineral; e pela produção de insumos e bens industriais intermediários; e pela reestruturação e nova rodada de expansão para a periferia, da indústria automobilística internacional. No período dos Governos do Partido dos Trabalhadores ( $\mathrm{PT}$ ), o país chegou a figurar entre as seis maiores economias mundiais, tornando-se um dos maiores exportadores mundiais de produtos minerais e agroindustriais. O ERJ participou dessa estratégia como corredor de exportaçóes de parte dessa pauta, e como produtor de aço e de petróleo.

A crise internacional de 2008 e a consequente desaceleração da economia mundial atingiram o país de forma mais dura, a partir de 2014, particularmente com a queda vertiginosa dos preços internacionais do barril de petróleo e com a desaceleraçáo no crescimento econômico da China. Isso produziu fortes impactos na cadeia de fornecimento a esse segmento, bem como na demanda internacional pelas principais commodities da pauta de exportaçóes. Até então, o Governo Federal implementara um conjunto de políticas anticíclicas, de corte keynesiano, que conseguiu manter estáveis o crescimento econômico, o consumo, o emprego e a renda, através de estímulos ao crédito popular, de aumentos reais do salário mínimo, do Bolsa-Família, de subsídios a segmentos empresariais e de encomendas de governo ao setor privado. O Programa de Aceleração do Crescimento (PAC), e o Programa de Habitação Minha Casa Minha Vida (pMCMv) são exemplos.

A crise brasileira atingiu gravemente o ERJ, cuja economia tornara-se altamente dependente da indústria do petróleo - cerca de 33\%, em 2014, conforme declaração do secretário estadual Júlio Bueno, em 4/01/2015 (Associação Comercial do Rio de Janeiro [ACRJ]), 2015) - e, particularmente, das suas rendas, concentradas no orçamento estadual e em uma dúzia dos seus 92 municípios. Em entrevista ao jornal Valor, no dia 14/05/2015 (p. A14), o governador Pezáo disse que, "incluindo estaleiros, fábrica de sonda, toda a cadeia produtiva representa $33 \%$ do pIB estadual” (Pessanha, 2015). Com 8,4\% da população e 11,2\% do PIB do país, o ERJ recebia, em 2008, 75,4\% das rendas petroliferas, que consistiam em royalties e participaçóes especiais, referentes a um percentual adicional nos poços mais rentáveis (Gobetti, 2011). Desde 2010, entretanto, a produção do petróleo extraído da camada do pré-sal vem deslocando o centro da produção para o litoral de São Paulo (SP), e parte do litoral do ERJ, diminuindo a participação deste na produção e nas rendas. A partir de 2017 vem ocorrendo gradativa recuperação dos preços internacionais, embora os poços do Norte Fluminense (NF) estejam em estágio de maturação, necessitando de investimentos para recuperarem os níveis de produção.

Mesmo antes de a crise mundial atingir o país e, no caso particular aqui analisado, o ERJ, existe um debate acerca das opçóes nacionais de políticas e açôes 
voltadas para o crescimento econômico, caracterizadas como constituintes de um modelo de reprimarização da economia, apoiado na exportação de produtos primários e semi-industrializados. A discussão extrapola as fronteiras nacionais e assume centralidade na discussão internacional sobre o desenvolvimento dos países periféricos, emergentes, de baixa industrialização, dependentes, ou subdesenvolvidos, nas atuais condiçóes da reproduçáo ampliada do capital no nível global. O domínio do capital financeiro especulativo e fictício, que impóe políticas neoliberais, ainda mais concentradoras e centralizadoras, articuladas a restriçóes dos direitos, da cidadania e da democracia. Capital e tecnologia se concentram cada vez mais e a escala de reprodução é crescentemente global. As consequências geopolíticas se expressam no agravamento de tensóes localizadas, orientadas pelos interesses das maiores potências internacionais por fontes de energia, matérias primas e insumos estratégicos para a acumulação capitalista, gerando enormes conflitos sociais, com deslocamentos forçados de populaçóes.

À luz de tais reflexóes, este artigo analisa a dinâmica econômica recente do ERJ, sob a perspectiva do padrão de crescimento econômico brasileiro, focando no processo em curso no norte do estado, através de dois Grandes Projetos de Investimento (GI) estratégicos para o padrão de integração internacional da economia brasileira. Serão apontados os impactos socioespaciais, expressos principalmente na dinâmica populacional, das rendas petrolíferas e do mercado de trabalho, bem como seráo identificados alguns conflitos dele decorrentes. Busca-se, com os casos analisados, contribuir para as reflexóes acerca das tendências e implicaçóes da participação das economias periféricas na nova Divisão Internacional do Trabalho (DIT).

São eles o Complexo de Exploração e Produção-E\&P off shore de Petróleo e Gás da Bacia de Campos, e o Complexo Industrial e Portuário do Açu (CıPA), localizados na mesorregião NF, onde se encontra a Bacia Petrolífera de Campos, num vetor territorial que desemboca na RMRJ (Cruz, 2016). Apesar da queda nos preços internacionais e da consequente crise dos orçamentos do estado e dos municípios fluminenses dependentes das rendas, a crescente exploração e produção off shore na camada do pré-sal, em áreas confrontantes com o Rio de Janeiro e outros quatro estados, deverá colocar o país entre os seis maiores em reserva e entre os maiores exportadores do mundo. O megaporto do Açu é um dos maiores do mundo, tendo suas atividades ancoradas no apoio às atividades de E\&P de petróleo e gás offshore e na exportação de minério de ferro, do qual o Brasil é o maior exportador mundial. Conta com instalaçóes para operar com contêineres e granéis sólidos e líquidos, além de possuir um Distrito Industrial (DI) anexo, fazendo parte da constituição de um Complexo de Logística Portuária e Produção Industrial, embora esta última ainda esteja apenas na fase inicial. A figura 1 apresenta a divisão regional do ERJ, permitindo identificar a regiáo NF e a RMRJ. 


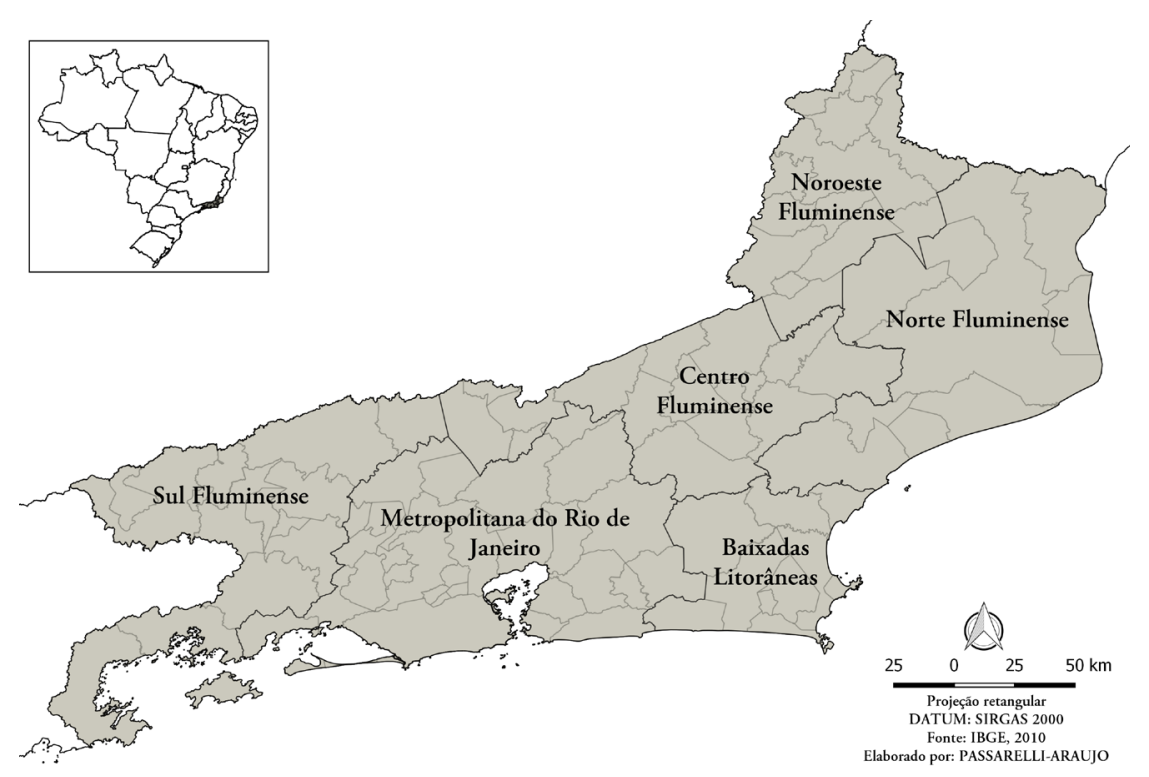

FIgURA I | Estado do Rio de Janeiro e suas mesorregióes

FONTE: IBGE,2OIO, ELABORADO POR PASSARELLI-ARAÚJO

As questôes para cujo debate este trabalho pretende contribuir são: quais os impactos que o modelo de GI em infraestrutura de produção e logística nos segmentos que integram internacionalmente os países da periferia na nova DIT, produzem nas estruturas e dinâmicas socioespaciais locais e regionais? Quais as contribuiçóes dessa reflexão para tratar a questão do desenvolvimento dos países periféricos, nesse contexto?

Na seção 2, a seguir, será traçado um breve perfil da ordem capitalista atual, no que diz respeito ao papel dos países de capitalismo periférico, detendo-se, no caso da América Latina (AL), na nova DIT, e, no caso brasileiro, analisado através de detalhamento dos aspectos ligados aos investimentos selecionados, no que diz respeito aos impactos provocados no território, no ambiente e na sociedade. A seção 3 analisa os casos pesquisados, detalhando os aspectos que tratam das questôes aqui levantadas, terminando com a identificaçáo de quatro dos grupos sociais mais afetados. $\mathrm{Na}$ Seção 3, serão feitas, como considerações finais, algumas reflexôes sobre as questôes que se colocam para o desenvolvimento na periferia capitalista, a partir dos dois casos tratados, enquanto exemplos da nova ordem econômica mundial.

\section{A nova ordem capitalista e a inserçáo da periferia: América Latina e Brasil}

Após cerca de três décadas de hegemonia neoliberal no comando da economia e da política mundiais, com nuances relativas aos blocos de países europeus, asiáticos e das Américas, há uma percepção, reforçada por pesquisas e relatórios de instituições multilaterais, de assessoria e consultoria (Pikety, 2014), de que houve um aumento 
das desigualdades sociais e de renda, assim como houve um aumento e aceleração da concentração de capitais, uma radicalização e aprofundamento da hierarquia entre naçóes, um agravamento, em escala mundial, incluindo os países centrais, do desemprego estrutural/tecnológico, da precarização nas relaçóes de trabalho, nas barreiras às entradas de capitais nos segmentos mais lucrativos e tecnológicos, bem como um crescente descrédito nas instituiçôes e nas regras do jogo democrático. Em suma, o saldo de três décadas de globalizaçáo é um mundo mais injusto, mais apartado, mais seletivo, mais violento e mais fragilizado politicamente.

Há uma megaconcentração de capitais, subordinados à dinâmica dos capitais fictícios, rentistas, que, agregados em megafundos financeiros (Pessanha, 2019), respondem pela propriedade dos ativos que regem o ritmo, a direção e o sentido da economia mundial. Uma das características do comando dos fundos de investimentos é que, através da participação acionária e financeira, conseguem assentos nos Conselhos de Administração das corporaçóes e holdings de um mesmo setor, ramo e segmento, resultando no que alguns autores denominam "capitalismo de laços" (Lazzarini, 2011), que neutraliza a concorrência e permite a organização de cartéis. Na verdade, há a reiteração dos oligopólios e monopólios em segmentos estratégicos para a reprodução ampliada dos capitais, como aponta a tabela 1 .

\begin{tabular}{|l|c|c|}
\hline \multicolumn{1}{|c|}{ SETOR } & No DE EMPRESAS & \% DO MERCADO \\
\hline Equipamentos agrícolas & 3 & 69 \\
\hline Farmacêutica & 10 & 69 \\
\hline Computadores pessoais & 4 & 55 \\
\hline Equipamentos de telefonia móvil & 3 & 77 \\
\hline Automóveis & 10 & 77 \\
\hline Avióes comerciais de grande porte & 2 & 100 \\
\hline
\end{tabular}

TABELA I | Grandes empresas e participação no mercado mundial.

Setores selecionados, 2009

FONTE: NOLAN E ZHANG (2OIO)

Percebe-se, na tabela 1, que a concentração na área dos equipamentos agrícolas torna as economias periféricas, como as da América Latina-AL, fortemente apoiadas na exportação de produtos agrícolas, vulneráveis ao controle tecnológico externo às naçóes. Ferramentas estratégicas para a economia mundial, como a indústria da computação e da telefonia móvel, também são controladas por poucos grupos.

A adoção, muitas vezes com característica de imposição, de políticas de recorte neoliberal, com adaptaçóes nacionais decorrentes das relaçóes de forças, da história, da cultura e da sociabilidade locais/nacionais, tem sido assimétrica, entre países que sediam os principais capitais e agentes corporativos, de um lado, e, de outro, países sem força para traçarem, com autonomia, políticas de integraçáo soberanas na economia globalizada. Os expedientes neoliberais de flexibilização da produçáo e da circulação de mercadorias, bem como de desregulação da dinâmica econômica, trabalhista e fiscal promoveram uma Divisão Internacional do Trabalho (DIT) radicalizada, em termos das especializaçôes produtivas. 
Os centros nacionais dos capitais financeiros e corporativos especializam-se em indústrias e serviços sofisticados, de alta densidade tecnológica, na economia "limpa", em processos "pós-fordistas" e na "economia do conhecimento", enquanto os países fora dos centros de decisão e de concentração dos capitais especializam-se na produção de bens primários e intermediários - minerais, agroindustriais, siderúrgicos, entre outros; ou, na "indústria suja", remanescente do fordismo. $\mathrm{O}$ aspecto central a ser considerado nessa ordem econômica é que os segmentos estratégicos são controlados por poucos capitais de escala global. Além disso, as tecnologias mais importantes para a economia capitalista também estấo concentradas, e os fundos de investimento globais controlam esses segmentos. É importante esse registro para se pensar nas possibilidades do desenvolvimento numa ordem em que as naçóes periféricas estejam cada vez mais dependentes em tecnologia e capitais.

$\mathrm{Na}$ AL, após governos que, na década de 1990, se propuseram a integrar os países de forma subordinada na ordem neoliberal globalizada - desregulando, privatizando, promovendo ajuste fiscal e internacionalizando segmentos internos da agroindústria e da indústria, o que gerou o agravamento das situaçóes históricas de desigualdade social e espacial - houve uma onda de governos, na Venezuela, Bolívia, Brasil, Equador, Chile, Uruguai, Argentina, e em países do Caribe, como El Salvador e Nicarágua, voltados para o que seria a elaboração de um conjunto de políticas "pós-neoliberais" (Sader \& Gentili, 1995). Esses governos estavam comprometidos com políticas sociais e de transferência de renda, de recorte distributivo e com formação de superavit comerciais, com o aumento da presença do Estado, ao mesmo tempo em que náo abandonaram políticas com recortes de ajuste fiscal, para cobrir o déficit fiscal e pagar os juros da dívida pública.

Coube a esses países, após o processo de desindustrialização e desnacionalização de amplos setores da economia nacional, expandirem a produção de commodities minerais e do agronegócio, para exportação. Na tabela 2, pode-se observar que, após um movimento ascendente de participação no PIB mundial, entre 1970 e 2000, houve uma reduçáo do peso das economias latino-americanas e caribenhas, o que sugere que a nova DIT, que reposiciona esses países como exportadores de produtos primários e industriais de menor densidade tecnológica, pode indicar um reforço ao "sistema internacional de trocas desiguais" denunciado pela Comissão Econômica para a América Latina e Caribe (CEPAL, 1951).

\begin{tabular}{|l|r|r|r|r|r|r|}
\hline \multicolumn{1}{|c|}{ PAÍ́s } & I970 & I980 & \multicolumn{1}{|c|}{ I990 } & 2000 & 20 I0 & 2015 \\
\hline América do Norte & 39,45 & 28,12 & 29,14 & 33,10 & 25,26 & 26,56 \\
\hline América Latina e Caribe & 5,96 & 6,93 & 5,17 & 6,79 & 8,18 & 7,01 \\
\hline Ásia Oriental e Pacífico & 13,72 & 16,17 & 20,94 & 24,41 & 25,40 & 28,98 \\
\hline Oriente Médio e Norte da África & 1,35 & 3,58 & 2,41 & 2,90 & 4,18 & 4,24 \\
\hline África Subsaariana & 2,08 & 2,40 & 1,36 & 1,10 & 2,06 & 2,14 \\
\hline Europa e Ásia Central & 34,13 & 40,76 & 39,15 & 29,78 & 31,73 & 27,22 \\
\hline Ásia Meridional & 2,94 & 2,14 & 1,83 & 1,89 & 3,19 & 3,63 \\
\hline Mundo & 100,00 & 100,00 & 100,00 & 100,00 & 100,00 & 100,00 \\
\hline
\end{tabular}

TABela 2 | Participaçáo das regióes do mundo no PIB mundial (em \%)

FONTE: BANCO MUNDIAL. DISPONÍVEL EM DATABANK.BANCOMUNDIAL.ORG/. ACESSO EM 27 JUL. 20 I 6 
A tabela 2 demonstra que, reforçando tal inferência quanto à evolução da participação das exportaçóes de produtos primários, em relação ao total, por países, em países selecionados - Argentina, Bolívia, Brasil, Chile, Colômbia, Equador, México, Uruguai e Venezuela - houve, após significativa redução dessa participação, entre 1970 e 2000, um importante aumento entre 2000 e 2014, em todos eles (CEPAL-Cepalstat, 2015), ao mesmo tempo em que houve queda na participaçáo no PIB.

Outra face dessa integração internacional subordinada dos países periféricos é a implantação de uma rede de infraestrutura de grande porte, voltada, internamente, para a otimizaçáo dos fluxos das mercadorias que respondem pela sua posição na DIT; e, externamente, para promover corredores de circulação de mercadorias que reduzem os custos na relaçáo espaço/tempo. Ao mesmo tempo, favorecem a concorrência pelo controle do comércio mundial por parte dos seus principais protagonistas, como EUA, China, uE e Rússia. É o que se passa com a duplicação da capacidade de trânsito e carga do Canal do Panamá, da ligaçáo entre os países do Pacífico, da ligação entre este e o Atlântico, por outro canal projetado pela China, na América Central, dentre outros (Ferchen, 2011; Intelego-Latam, 2013; Núcleo Amigos da Terra [NaT] Brasil, 2006; Pessanha, 2015).

Nesse sentido, o Brasil vem investindo pesadamente em grandes projetos de infraestrutura, como estratégia - no Governo Fernando Henrique Cardoso (FHC), com os Planos Brasil em Ação e Avança Brasil; nos governos do PT, com o PAC I e PAC II, articulado com o Plano Nacional de Logística de Transporte (PNLT) (Ministério da Infraestrutura, 2011), com os Programas de Investimento em Ferrovias, Rodovias e Portos - articulando os capitais nacionais associados, ou subordinados, aos transnacionais. A figura 2 apresenta o mapa dos investimentos ferroviários previstos.

$\mathrm{Na}$ figura 2 está destacada a localização da área do estado do Rio onde se encontram os dois GIs aqui analisados, o Complexo de E\&P e o CIPA. Pode-se perceber sua posição estratégica na rede de ferrovias de escoamento da produção mineral e agroindustrial do interior do país. São estruturas desproporcionais em relação às dimensóes e capacidade das localidades para suportar seu porte. Há ausência das necessárias intervençóes de planejamento e desenvolvimento territorial, urbano e regional, preventivas e mitigadoras, em decorrência da natureza das coalizóes de interesses multiescalares constituídas, e da adesão passiva de autoridades e populaçôes locais, manipuladas pela propaganda feita pelas mídias, pelos porta-vozes, lideranças, e acadêmicos ufanistas. São investimentos comandados de "fora" e voltadas para "fora”, numa lógica que se desresponsabiliza da integração com o território, região e aglomeraçóes urbanas onde se situam as instalações físicas, restringindo ou inviabilizando a regionalização e territorialização dos possíveis benefícios. São portadores de uma visão puramente mercantil e rentista, pela qual "otimizam" os projetos, no sentido da garantia de que nenhum interesse público, social, coletivo, possa comprometer as expectativas das taxas de lucro prometidas pelos investimentos. Sustentam-se em renúncia fiscal, subsídios, omissóes e cumplicidades dos órgãos públicos de fiscalização referentes aos danos sociais, trabalhistas, urbanos, ambientais, econômicos, culturais e políticos. 


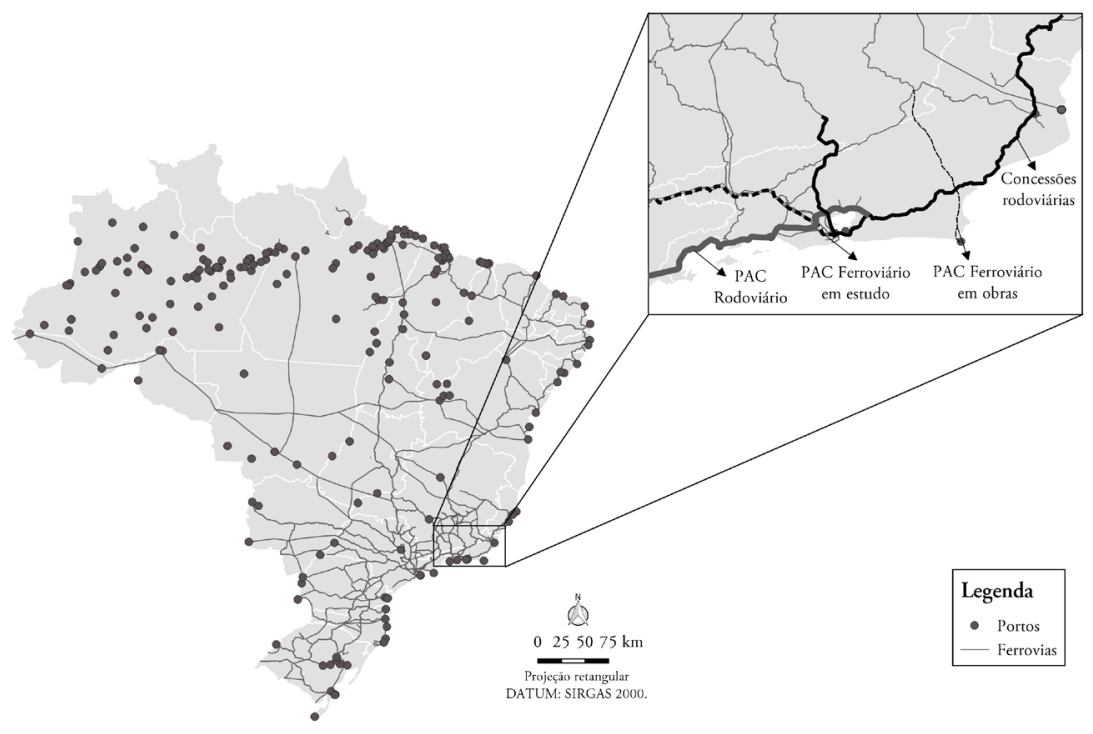

FIGURA 2 | Mapa dos investimentos ferroviários previstos

FONTE: PLANO NACIONAL DE LOGÍ́tica DE TRANSPORTE (PNLT), MiNistéRIO DOS TRANSPORTES, GOVERNO FEDERAL, BRASIL. EM HTTP://WWW2.TRANSPORTES.GOV.BR/BIT/OI-INICIAL/PNLT. HTML

Ocorre o que diversos autores denominam reprimarização das economias latino-americanas, como forma de integrá-las à globalização controlada pelos capitais financeiros, pelos oligopólios mundiais de investimento, produção e circulação de mercadorias, no interesse do barateamento dos custos dos produtos primários e da reprodução das formas colonialistas/imperialistas contemporâneas. Nesse cenário se dá o aprofundamento da internacionalização das economias da América Latina nos anos de neoliberalismo, agravado pelo ajuste fiscal, nos ditames do Consenso de Washington, adotado em maior ou menor grau por governos latino-americanos, desde os mais afinados com o neoliberalismo até os que se consideram de recorte pós-neoliberal, desenvolvimentistas, keynesianos e "populares" (Filgueiras, 2006; Gonçalves, 2012; Sampaio Jr., 2012).

Com a crise iniciada em 2008, que reduziu o volume do comércio mundial, quem mais perdeu foram os países dependentes das exportaçóes de commodities minerais e agroindustriais. A América Latina tornou-se o maior exportador líquido de alimentos do mundo, ultrapassando a América do Norte no início dos anos 2000 e, desde essa data, mostra tendência de crescimento, de acordo com o relatório da Organização das Naçôes Unidas para Alimentação e Agricultura (FAO), lançado em dezembro de 2015. No entanto, a desaceleração recente da economia chinesa, somada à guinada para a direita em diversos governos de países latino-americanos, com destaque para Argentina e Brasil, provocaram uma perda do dinamismo recente dessas economias, bem como um abandono das estratégias neodesenvolvimentistas. Tais movimentos das conjunturas podem ser percebidos nos dois casos aqui analisados. 


\section{O ERJ como expressão do “caso" brasileiro: petróleo e porto, impactos e conflitos}

Os GIs espalham-se pelo território brasileiro. No Norte, compreendem empreendimentos de geração de energia, viários, portuários, minerais, agropecuários, de exploraçáo florestal; no Nordeste, viários, portuários, minerais, industriais; no Centro-Oeste, de geração de energia, viários, do agronegócio; no Sudeste e no Sul, epicentro da economia nacional, de minerais, viários, do agronegócio, industriais, portuários (Ministério da Infraestrutura, 2011).

O território do ERJ é atravessado por GIs viários, portuários, minerais, industriais e de turismo. É representativo não só pela diversidade, mas principalmente pelo porte, figurando entre os mais importantes do país. Grande parte localiza-se fora da capital - Rio de Janeiro - e da RMRJ com destaque para a indústria do petróleo \& gás, automotiva e para a infraestrutura de logística; e na capital, em intervençóes urbanas realizadas recentemente, voltadas para grandes eventos, entre os quais se destacaram a Copa de Mundo de futebol e a Olimpíada mundial. Os empreendimentos industriais e urbanos se associam ao conjunto de obras de infraestrutura em curso no estado, de suporte físico à circulação de mercadorias vinculadas a grandes investimentos produtivos nacionais. O uso do território do ERJ será intensificado, como plataforma de corredores nacionais de exportaçáo e importação, previstos nos PNLT, no PAC e nas açóes setoriais apoiadas pelo Banco Nacional de Desenvolvimento Econômico e Social (BNDES) (figura 3).

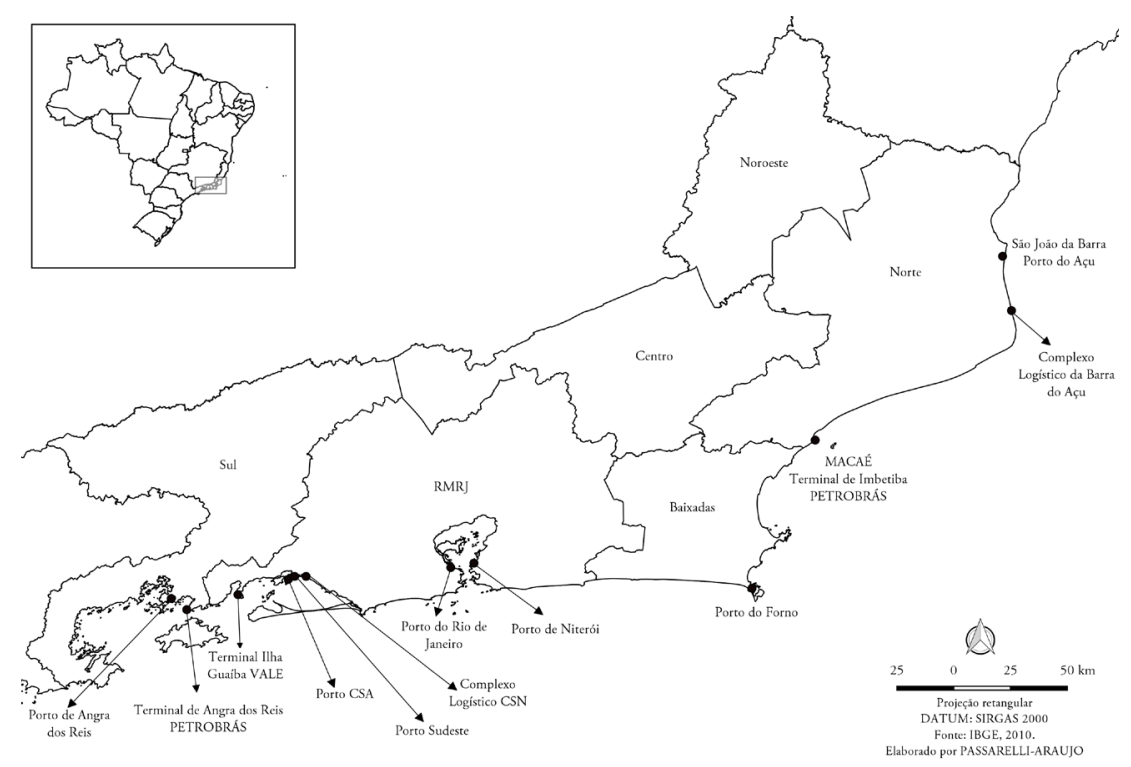

FIGURA 3 | Grandes Investimentos em logística portuaria no ERJ

FONTE: ELABORAÇÃo PRÓPRIA. FEDERAÇÃo DAS INDÚSTRIAS DO ESTADO DO RIO DE JANEIRO (FIRJAN) (2OI 2). FILE:///C:/USERS/USER/DOWNLOADS/DECISAO\%2ORIO\%2O2OI 2-2OI 4.PDF) 
O Complexo de Exploração e Produção de Petróleo e Gás (E\&P) foi instalado no município de Macaé, gerando dezenas de milhares de empregos diretos, na Petrobras - até 1997, detentora do monopólio da exploração e produção - e nas demais petroleiras, e nas centenas de empresas fornecedoras de serviços e de equipamentos à produçáo. Até 2012, a produção do ERJ representava cerca de $80 \%$ do total nacional. Com a exploração do petróleo da camada do pré-sal, cuja bacia se estende ao sul do Brasil, sua participação caiu (agosto/2016), para algo em torno de $55 \%$ do total nacional. Diversos fatores concorreram para que essa experiência estadual como maior produtor nacional de petróleo viesse a produzir - ao lado dos impactos positivos na geração de trabalho e renda - impactos socioespaciais altamente desestruturantes, no que diz respeito às atividades econômicas, ao ambiente natural e às estruturas e dinâmica urbana.

Entre os mais importantes para o objetivo deste artigo figuram: i) a concentração espacial das empresas em um só município, promovendo uma fragorosa implosão urbana, em um curtíssimo período de tempo, em Macaé e em alguns dos municípios produtores concentradores das rendas. Estes, entre 2000 e 2010, situaram-se entre os municípios de maior crescimento demográfico do país, agravando problemas de infraestrutura, moradia, mobilidade e segurança para a população trabalhadora, apresentando sérios problemas de pobreza e desigualdade social; ii) a configuração de um enclave econômico, na medida em que náo se implantaram atividades industriais upstream e downstream, ou, a montante e a jusante das atividades locais de E\&P; iii) a geração de municípios petrorrentistas, ou seja, recebedores de ricas rendas petrolíferas, sem que houvesse crescimento, integração ou diversificação das atividades produtivas, ou planejamento das suas aplicaçôes. Por um lado, esses municípios se tornaram altamente dependentes das rendas petrolíferas, e, por outro, incapazes de desenvolver atividades complementares, ou alternativas, geradoras de fontes diferenciadas de arrecadação própria; iv) monopólio exercido sobre os recursos existentes e os novos recursos, pelas atividades da indústria extrativa regional de petróleo, mobilizando-os para atividades subsidiárias de baixa tecnologia e de baixo rendimento, inibindo outras atividades, no que se poderia classificar como uma nova forma de monocultura; v) impactos ambientais negativos de grande monta, com elevados prejuízos para atividades econômicas regionais de elevada importância social, como a pesca artesanal, com a restrição das áreas de pesca, a ampliação do perímetro a ela proibido - onde muitas vezes se instalam importantes pesqueiros, devido à rede de tubos submarina, quase no nível da superfície, causando prejuízos aos barcos pesqueiros, ameaçando a viabilidade da pesca artesanal regional, no médio prazo.

A dimensão rentista dessa economia regional, dependente das rendas da E\&P, traz insegurança, na medida em que não gera integração e encadeamento produtivo, através de atividades industriais a montante e a jusante. Os municípios dependentes das rendas defrontaram-se, entre o final de 2014 e o início de 2018 - quando então os preços internacionais voltaram a subir - com a tragédia, até hoje não superada, da redução drástica e brusca das suas rendas, decorrentes da baixa dos preços internacionais do petróleo, sobre os quais os valores sáo calculados (Piquet, 2007), como ilustra a tabela 3, a seguir. 


\begin{tabular}{|c|c|c|c|c|}
\hline \multirow{2}{*}{ MUNICÍPIO } & \multicolumn{4}{|c|}{$\begin{array}{c}\text { TRANSFERÊNCIA DE ROYALTIES E PARTICIPAÇÓES ESPECIAIS (EM } \\
\text { MIL REAIS, CORRIGIDOS PELO IGP-DI) }\end{array}$} \\
\hline & 2010 & 2014 & 2016 & 2018 \\
\hline Campos dos Goytacazes & 1.718 .046 & 1.605 .047 & 397.863 & 709.567 \\
\hline Macaé & 701.740 & 732.002 & 300.230 & 636.013 \\
\hline São João da Barra & 342.933 & 314.720 & 101.461 & 171.698 \\
\hline Total & 2.762 .719 & 2.651 .769 & 799.554 & 1.517 .278 \\
\hline
\end{tabular}

TABELA 3 | Evoluçáo das transferências de royalties e participaçóes especiais (em mil reais) da produçáo petrolífera para os municípios do NF Selecionados

FONTE: INFO ROYALTIES. HTTPS://INFOROYALTIES.UCAM-CAMPOS.BR/

Observa-se, na tabela 3, que em 2014, apesar da queda nos preços se acentuarem no final do ano, o total anual já reflete ambos, a estagnação e queda lenta na produção e a baixa nos preços, ao final do ano. Ainda na tabela 2 pode-se constatar a drástica redução em 2016 e a elevação em 2018. Em 2016 a queda nos nos preços e na produçáo são os principais fatores; já 2018 houve uma significativa recuperaçáo dos preços internacionais do petróleo.

Já o Complexo Portuário Industrial do Açu-CipA é um empreendimento da PRUMo Logística, pertencente ao Fundo de Investimento americano EIG (Energy Investment Group). É um megaporto que pode receber supernavios de até 320 mil toneladas de carga. Opera com exportação de minério de ferro, oriundo do estado de Minas Gerais, que chega ao porto através de um mineroduto de $525 \mathrm{~km}$ de extensão - considerando o maior do mundo - atravessando 32 municípios de 3 estados; e com apoio às atividades off shore de produção do petróleo da Bacia de Campos. Tem dois terminais, com capacidade para operar com grãos, líquidos e gases, e contêineres. Seu Complexo Industrial consiste num Distrito Industrial e numa retroárea. No total, abarca uma área equivalente a um terço do município de São João da Barra. Estão previstas as construçóes de um Corredor Logístico, com ferrovia e rodovia próprios, e entroncamentos rodoviários e ferroviários que o tornarão um escoadouro de alguns dos principais centros produtores de commodities do país, conforme assinalados na figura 2 aqui apresentada.

Dentre os seus principais impactos negativos encontram-se: i) deslocamento forçado e violento de centenas de famílias de pequenos produtores e produtores familiares agrícolas e agropecuários tradicionais, de um distrito rural do município, junto ao litoral, para implantação do Distrito Industrial; ii) destruição de lagoas e áreas de restinga destinadas à preservação e proteção; salinização do lençol freático pelo depósito de sedimentos do fundo do mar em terra firme, inviabilizando atividades agropecuárias; iii) inviabilização da pesca, devido ao amplo perímetro de operação do porto; iv) configuração de um enclave, como no caso do Complexo de E\&P, pelo fato de que os portos, contemporaneamente, náo interagem positivamente com a cidade e com o seu entorno (Monié \& Vidal, 2006; Pessanha, 2017). No entanto, são capazes de exercer um grande poder de atração de força de trabalho, provocando impactos negativos sobre a infraestrutura e a vida urbana, tais como 
precariedade dos serviços, problemas de moradia, de segregação socioespacial, de mobilidade, de pobreza e violência, como já são observados e analisados no município de S. João da Barra (Pedlowski, 2013); v) elevada capacidade de mobilização de recursos locais para atividades subsidiárias de baixa tecnologia e de baixo rendimento, semelhante ao GI de E\&P de petróleo e gás.

No que diz respeito à dinâmica urbana, o rápido e intenso afluxo de trabalhadores provocou uma total reconfiguração funcional da rede regional de cidades. As características concentradoras, de enclave e de elevada polarização das estruturas econômicas montadas em Macaé, a partir de 1977 - de exploração e produção de petróleo e gás - e em São João da Barra, a partir de 2007 - do complexo portuário - transformaram esses dois municípios, pequenos e pouco populosos, em polos de trabalho e atividades empresariais. Campos dos Goytacazes sofreu menos, por ser o maior, o mais antigo polo regional e possuir a maior, melhor e mais diversificada rede de infraestrutura urbana, de comércio e serviços, também.

Campos dos Goytacazes, tradicional e maior polo regional durante mais de três séculos, reflete essa dinâmica espacialmente concentrada. Com a derrocada da economia agroindustrial de açúcar e álcool, no final da década de 80 , o ritmo do seu crescimento demográfico só se elevou quando ocorreu a elevação do percentual da produção referente às rendas petrolíferas recebidas pelo município, a partir de 1999 . Por ter a maior área confrontante com a Bacia de Campos, é o maior recebedor nacional de rendas do petróleo, o que eleva artificialmente o seu PIB, figurando entre os maiores PIBs. Possui uma infraestrutura urbana complexa e diversificada, situando-se entre os municípios de São João da Barra e Macaé e possuindo mais do dobro da população somada desses dois. É o maior município do interior do estado. A atividade produtiva do Complexo de E\&P, somente, náo foi capaz de alterar a dinâmica demográfica, corroborando o argumento de que esses GIs possuem diversas características de enclaves (Piquet, 2007).

\begin{tabular}{|c|c|c|c|c|c|}
\hline \multirow{2}{*}{$\begin{array}{c}\text { MUNICÍPIOS } \\
\text { SELECIONADOS DO } \\
\text { NF, ESTADO DO RIO } \\
\text { DE JANEIRO E BRASIL }\end{array}$} & \multicolumn{3}{|c|}{ POPULAÇÁO TOTAL } & \multicolumn{2}{|c|}{$\begin{array}{c}\text { TAXA DE CRESCIMENTO } \\
\text { MÉDIO ANUAL (\%) }\end{array}$} \\
\hline & 2000 & 2010 & 2018 & $2000-2010$ & $2010-2018$ \\
\hline Campos dos Goytacazes & 406.989 & 463.731 & 503.424 & 1,31 & 1,03 \\
\hline Macaé & 132.461 & 206.728 & 251.631 & 4,55 & 2,49 \\
\hline São João da Barra & 27.682 & 32.747 & 36.138 & 1,69 & 1,24 \\
\hline Estado RJ & 14.391 .282 & 15.989 .929 & 17.159 .960 & 1,06 & 0,89 \\
\hline Brasil & 169.799 .170 & 190.755 .799 & 208.494 .900 & 1,17 & 1,12 \\
\hline
\end{tabular}

TABELA 4 | Crescimento populacional desde 2000-Brasil, ERJ e Municípios Selecionados do NF

FONTE: CENSO DEMOGRÁFICO E ESTIMATIVAS. IBGE - INSTITUTO BRASILEIRO DE GEOGRAFIA E ESTATÍSTICA, EM JUNHO 2OI9. HTTPS://WWW.IBGE.GOV.BR/ESTATISTICAS/SOCIAIS/POPULACAO /9IO3-ESTIMATIVAS-DE-POPULACAO.HTML?=\&T=O-QUE-E 
A tabela 4, a seguir, apresenta o crescimento populacional dos municípios que concentram os investimentos relacionados à indústria extrativa petrolífera e ao Complexo Portuário do Açu, e o de Campos dos Goytacazes. São municípios contíguos. Campos dos Goytacazes é o maior, mais populoso e o tradicional polo regional, concentrando infraestrutura diversificada, situando-se estrategicamente entre os dois outros municípios e às margens da mais importante rodovia do país - a BR-IOI - o que o leva a beneficiar-se do crescimento dos serviços e comércio relacionados aos dois Grandes Empreendimentos aqui analisados. Macaé é a sede da maioria das empresas que prestam serviços às atividades off shore e onde se encontram as instalaçôes da Petrobras. São João da Barra é o município que sedia as instalaçóes do Porto do Açu.

A tabela 4 revela que, entre 2000 e 2010, as taxas de crescimento médio anual da população do três municípios foram superiores às do estado e do país. Esse período é marcado pelo aumento fabuloso das rendas petrolíferas transferidas para esses municípios, situando-os entre os mais ricos do país; pela quebra do monopólio da Petrobras na Extração e Exploração do petróleo; e pelas obras de implantação do Porto do Açu. Esses três fatores explicam, ainda, a hierarquia entre as taxas dos três municípios. Macaé, que, além das transferências das rendas, passou a receber instalações de novas empresas petrolíferas, manteve um crescimento bem superior aos outros dois. Por sua vez, São João da Barra, que recebeu milhares de trabalhadores para as obras do Porto, teve taxa superior a Campos dos Goytacazes.

Já entre 2010 e 2018 diversos fatores e tendências explicam não só a queda das taxas em relação à década anterior, aproximando as taxas de sJB e de Campos às do estado e do país: a taxa de Campos, próxima à do estado e inferior à do país; a taxa de Macaé, ainda mais do que o dobro da do estado e do país; e a taxa de sJB, ligeiramente superior às do estado e do país. Os principais fatores são: i) em 2013, o Porto do Açu foi vendido ao Fundo EAG, tendo seu projeto inicial drasticamente reduzido; ii) em 2014, o Porto do Açu iniciou suas operaçóes, e milhares de trabalhadores que foram empregados nas suas obras, foram dispensados; iii) no final de 2014, os preços internacionais do petróleo foram drasticamente reduzidos; paralelamente, a produção de petróleo regional passou por estagnação e ligeira redução, por ser sustentada por poços maduros; ambos os fatores contribuíram para uma queda significativa nos valores dos royalties e participaçóes especiais transferidos aos municípios em questão, conforme ilustra a tabela 3, anterior a esta.

Com a evoluçáo do Porto do Açu, o município de Campos, pelo seu porte, localização e infraestrutura de comércio e serviços - é um grande centro de ensino profissional, técnico, sendo um dos maiores centros federais de formação profissional de nível médio e superior do país - vem se reforçando como polo regional, sediando unidades de logística de distribuiçáo de mercadorias e de moradia e de consumo sofisticados. Os GIs estáo produzindo três polos regionais, nesses três municípios, apontando para uma aglomeração urbano-regional ampla, com características de região metropolitana do interior, ou mesmo para uma megarregião, dada pelo vetor de conurbação que se estende até a região de produção do petróleo do pré-sal do Estado de São Paulo (sp) (Lencioni, 2015). 
Em 2015 o Instituto Brasileiro de Geografia e Estatística (IBGE) publicou o documento "Arranjos Populacionais e Concentraçôes Urbanas do Brasil”, uma referência para a compreensão da reestruturação do espaço urbano brasileiro. Segundo o IBGE, existem no Brasil 294 arranjos populacionais (que envolvem um total de 938 municípios), espacialmente concentrados nas regiōes Sudeste (112 unidades) e Sul (85). A partir desses arranjos, foram definidas as concentraçôes urbanas, classificadas, segundo o tamanho populacional, em dois grupos: até 100 mil habitantes e acima de 100 mil habitantes. Essas últimas reclassificadas em concentraçóes urbanas de médio (entre 100 e 750 mil habitantes), e de grande (acima de 750 mil habitantes) porte. O IBGE define um arranjo populacional como "um agrupamento de dois ou mais municípios onde há uma forte integração populacional devido aos movimentos pendulares para trabalho ou estudo, ou devido à contiguidade entre as manchas urbanizadas principais" (Souza, Terra, \& Campos, 2015).

Os arranjos populacionais de Macaé e Campos dos Goytacazes (que abrange o município de sJв) foram sugeridos pelo IBGE (2015) como casos especiais a serem acompanhados, pois, "caso o dinamismo econômico nesta regiáo venha a aumentar o movimento de pessoas entre estes três arranjos, levará à criação de uma nova unidade urbana que somará mais de 1,2 milhão de habitantes”. Estes novos arranjos populacionais são fruto do processo de urbanização. Foram utilizados três critérios de integração para a identificação dos arranjos populacionais: i) forte intensidade relativa dos movimentos pendulares para trabalho e estudo, que deve ser igual ou superior a 0,25 do índice de integração; ii) forte intensidade absoluta dos movimentos pendulares para trabalho e estudo, igual ou superior a 10.000 pessoas; iii) contiguidade das manchas urbanizadas, quando a distância entre as bordas das manchas urbanizadas de dois municípios é de até $3 \mathrm{~km}$ (Cruz \& Terra, 2015).

Campos dos Goytacazes e Macaé-Rio das Ostras aparecem em primeiro e segundo lugar, entre as médias concentraçóes urbanas, com população acima de 300.000 até 500.000 habitantes, com os 10 maiores Produtos Internos Brutos (PIBs). Esses resultados refletem o elevado peso da atividade petrolífera na composição do PIB dessas três concentraçóes. Esse processo já apresenta impactos desestruturantes da vida urbana, agravados pela ausência de políticas de ordenamento territorial e urbano: i) há uma elevada concentração e valorização do solo urbano, com construção de imóveis voltados para a locação por parte de empresas e de trabalhadores de média e alta renda, elevando os preços; ii) em consequência, promove-se um processo crescente de deslocamento forçado de assentamentos urbanos de baixa renda, particularmente das favelas, de áreas destinadas à especulação imobiliária; os novos projetos habitacionais populares distanciam-se cada vez mais das áreas beneficiadas com infraestrutura, particularmente de transporte coletivo, e próximas dos locais de trabalho, dos serviços e do consumo, aprofundando a segregação socioespacial e gerando novas periferias, com o agravamento da desproteçáo às populaçóes mais pobres, submetidas a regimes de extrema violência; iii) instalam-se nessas áreas condomínios residenciais fechados de classes alta e média alta; shopping centers e hotéis de grandes redes nacionais e internacionais; condomínios verticais voltados para atividades comerciais; equipamentos de logística de armazenagem e distribuição de mercadorias, de grandes capitais nacionais e internacionais. 
O que se quer destacar é que o processo de apropriação do território pelos grandes capitais nacionais e internacionais se estende às atividades subsidiárias dos GIs, sobrepondo-se aos capitais de médio porte locais tradicionais, esvaziando o controle dos grupos sociais e do poder local sobre as dinâmicas urbana, econômica e de infraestrutura. Prevalece o padrão de "comando de fora das decisóes estratégicas" e de controle sobre a dinâmica territorial urbana e regional, a partir de fora e ditado pela dinâmica do mercado, ao sabor da instável, insegura e volátil economia internacional.

Quatro casos exemplares ilustram esse processo. O espaço deste artigo não permitirá uma análise e exposição profundas e detalhadas desses casos. Eles figuram aqui como exemplos do poder desestruturante que está na raiz desse modelo.

O primeiro é o das centenas de pescadores artesanais do litoral do Norte Fluminense. Inicialmente prejudicados pela implantação das plataformas marítimas e redes de tubos submarinos de E\&P de petróleo o gás, e, desde 2007, pela construção e operação, a partir de 2014, do Porto do Açu. Como a bacia tem mais de 100 mil km², 53 plataformas e mais de 500 poços (O Petróleo, 2018) o perímetro de proibição da pesca é imenso, além dos prejuízos causados aos barcos, em áreas permitidas, por dutos submarinos situados em baixa profundidade. No Açu, por questôes de segurança para as operaçôes, é também muito grande o perímetro, em torno das instalaçóes portuárias, que não pode ser acessado pelos pescadores. Ironicamente formam-se ricos pesqueiros nessas áreas. A licença ambiental exige medidas compensatórias e de mitigação, que, porém, são consideradas insatisfatórias pelos pescadores (Petrobras, 2014).

O segundo caso é o das centenas de pequenos produtores de alimentos no $5^{\circ}$ Distrito de São João da Barra, onde se localiza o Porto do Açu. A área, correspondente a $1 / 4$ do município, foi violentamente "desapropriada", em 2007 , por um órgão do estado, e repassada à empresa proprietária do Porto para a implantação de um Distrito Industrial (DI). Permanece vazia há 10 anos, rendendo 140 milhôes de reais por ano de aluguéis, pagos por empresas como reserva de área, ao Porto. Puro rentismo, gerado pela expropriaçáo de pequenos produtores, que se encontram em conflito, em alguns momentos aberto, sendo reprimidos por força policial, e com processo judicial de retomada das terras, cuja luta ainda está em curso (Costa, 2018).

O terceiro caso é o da Favela da Linha, a maior e mais antiga favela de Campos, cujos moradores foram removidos "à força” para uma área fora da cidade, sem infraestrutura e mobilidade, após longa resistência e luta, para dar lugar à incorporação da área para construção de condomínios residenciais e conjuntos comerciais e de serviços para classes de alta renda, na medida em que a cidade se consolida como sede das empresas que servem ao Porto e ao Complexo de E\&P e das grandes estruturas de comércio e serviços. Alguns moradores ainda residem e resistem na favela (Gonçalves, 2014).

O quarto e último exemplo é o da penetração do grande capital em serviços não mercantilizados. Trata-se do serviço de coleta de lixo. Centenas de catadores de lixo foram destituídos do trabalho, com o fechamento do depósito de lixo a céu aberto em Campos, em 2012. Desde então, travam uma luta para assumir a Coleta Seletiva do município, através de quatro cooperativas de trabalho formadas por eles, em 
disputa com uma empresa membro de um dos maiores conglomerados brasileiros, que possui a concessão do serviço, resistindo à captura desse serviço público por uma grande empresa (Almeida et al., 2016).

A ausência de políticas públicas voltadas para a preservação e fortalecimento de atividades econômicas tradicionais, como nos acasos aqui analisados, bem como para a sustentação da economia regional na diversidade de atividades para diminuir a dependência aos dois Grandes Projetos aqui abordados, que possuem diversas características de enclaves, reflete-se na relativa vulnerabilidade do mercado de trabalho, como se pode observar nos dados sobre a evolução recentedo estoque de emprego.

O mercado de trabalho formal de Macaé, que possuía um terço da população de Campos na implantação do Complexo e hoje possui ainda menos da metade, é quase o dobro do de Campos, em termos do número de empregos com carteira assinada. Abaixo, a tabela 5 apresenta a movimentaçáo recente do mercado de trabalho formal dos municípios aqui abordados.

\begin{tabular}{|l|r|r|r|r|}
\hline \multicolumn{1}{|c|}{$\begin{array}{c}\text { MUNICÍPIOS DO NORTE FLUMINENSE } \\
\text { SELECIONADOS }\end{array}$} & 20IO & $\mathbf{2 0 I 3}$ & 20I7 & \multicolumn{1}{c|}{$\mathbf{2 0 I 8}$} \\
\hline Campos dos Goytacazes & 87.380 & 98.220 & 85.303 & 68.366 \\
\hline Macaé & 115.775 & 144.627 & 113.996 & 102.123 \\
\hline São João da Barra & 7.397 & 9.691 & 9.007 & 7.957 \\
\hline Total & 210.552 & 252.538 & 208.306 & 178.446 \\
\hline
\end{tabular}

TABELA 5 | Evolução do Estoque de empregos formais nos Municípios do NF Selecionados

Fonte: Ministério do trabalho e EMPrego (MTE), governo Federal, Brasil. elaboração: A. CHAGAS E J. L. CRUZ. HTtP://TRABALHO.GOV.BR/PORTAL-MTE/

A tabela 5 revela que houve redução significativa no contingente de trabalhadores com emprego formal entre 2010 e 2018 . A drástica redução em 2017 e 2018 reflete a crise econômica em que o Brasil mergulhou após 2015, agravada pelo ajuste fiscal do Governo Temer, que congelou os gastos e investimentos federais por 20 anos. Embora náo se tenha dados para 2019, certamente o corte de $30 \%$ nas despesas correntes e investimentos realizado pelo Governo Bolsonaro, que tomou posse em janeiro de 2019, deverá acentuar ainda mais a reduçáo do mercado de trabalho regional, desmontando o projeto neodesenvolvimentista. No caso regional, o corte nos investimentos da Petrobras acrescentou impactos negativos a essa tendência. Mas, é a imprevisibilidade dos dois Grandes Projetos, altamente sensíveis à instabilidade da economia internacional, e a elevada dependência dos municípios da região às essas atividades que ameaçam o desenvolvimento do Norte Fluminense.

Segundo os estudos da Federação das Indústrias do Rio de Janeiro (FIRJAN), para o período 2012-2014 os investimentos previstos para o ERJ foram de $\mathrm{R} \$ 211,5$ bilhóes, cabendo $17,7 \%$ ao território do ERJ que vai do norte até a capital, pelo litoral, onde se encontra o Porto do Açu e a cadeia do Complexo de E\&P. Para o período 2014-2016 estavam previstos 11,3\% dos R \$255,6 bilhóes do total de investimentos no ERJ. A maior parte dos investimentos foram cortados, em decorrência da crise 
desencadeada ao final de 2014, já aqui abordada. Não houve estudos publicados para o período 2016-2018, provavelmente em decorrência da crise acentuada após 2015, que paralisou os investimentos. Para 2019 a aposta do Governo Federal na retomada da economia prevê investimentos de $\mathrm{R} \$ 162,2$ bilhóes, dos quais $13,8 \%$ para a região aqui analisada. Os investimentos mais prejudicados foram os da petroquímica, dada a crise da Petrobras; da indústria naval, dada a mudança na política de encomendas da indústria petrolífera, que se volta agora para compras no exterior; e em rodovias, ferrovias e novos portos e terminais portuários e aeroviários.

\section{Qual desenvolvimento?}

$\mathrm{O}$ artigo buscou contribuir para as reflexóes acerca das possibilidades de desenvolvimento na periferia do capitalismo através da integração na economia internacional por meio de grandes projetos vinculados à produção e circulação internacional de commodities do setor primário da economia. Para tanto, tratou de dois casos oriundos de pesquisas dos autores e de outros pesquisadores, representativos desse padráo de integração. ambos localizados no norte do ERJ, na regiáo Norte Fluminense.

As pesquisas evidenciaram que tal padrão de integração contém vetores de desestruturação socioepacial e econômica do território, por uma série de características inerentes aos Projetos, bem como ao processo de implantação e operação dos mesmos. Ao lado da pouca interação com o território, ocorrem deslocamentos forçados de população, agressóes severas ao meio ambiente, desestruturação de economias regionais, bem como barreiras à introdução da diversificação e/ou integração nas atividades dos GI. A dependência e a polarização provocam inseguranças nos municípios da região, altamente vulneráveis às instabilidades e imprevisibilidades decorrentes do grau de atrelamento dos municípios às dinâmicas dos GI. As crises econômicas, mundial e nacional, recentes, bem como, no caso do Brasil, as mudanças no Governo Federal, não só desmontaram o projeto neodesenvolvimentista como anunciam uma radicalização do processo de desnacionalização e desindustrialização.

Portadora de dois GI de projeção interncional, a regiâo vive uma profunda crise e um elevado grau de incerteza. Ao boom de crescimento populacional seguiu-se uma profunda oscilação nas rendas petrolíferas e no mercado de trabalho regional, expressa nos três principais municípios, aqui abordados.

Os casos aqui analisados são representativos, em linhas gerais, do padrão adotado pelo Brasil e diversos outros países da América Latina. Esses, no enfrentamento das desigualdades presentes nas estruturas subdesenvolvidas, realizaram esforços de políticas pós-neoliberais, na primeira década do presente século, combinando elementos distributivos, pela forte presença do Estado, de corte keynesiano, com políticas sociais de bem-estar, e superávit comerciais. Em meio às crises capitalistas recorrentes, no novo século, revelaram-se fortalecidos pelo incremento da produção de commodities minerais e do agronegócio para exportação. No entanto, a crise, a desaceleração da China e novos acordos de comércio tendem a desfavorecer o continente latinoamiericano, agravados pela guinada conservadora na política mundial e latino-americana e a questionar os caminhos escolhidos por esses países. 


\section{Referências bibliográficas}

Almeida, Erica T. V. de, Balthazar, A. C., Echkardt, A. P., Cordeiro, F. A., Figueiredo, S., Donato, N., (...) \& Santos, D. N. (2016). Protagonismo e esfera pública em Campos dos Goytacazes: a trajetória recente dos catadores do lixão da Codin. C. J. Pereira \& F. L. Goes (orgs.), Catadores de materiais recicláveis: um encontro nacional (pp. 293-308). Rio de Janeiro: Instituto de Pesquisa Económica Aplicada (IPEA). http://www.ipea.gov. $\mathrm{br} /$ portal/images/stories/PDFs/livros/livros/160331_livro_catadores.pdf

Associação Comercial do Rio de Janeiro (ACRJ). (2015). Entrevista com o Secretário Júlio Bueno. http://www.acrj.org.br/noticias/secretario-diz-nao-acreditar-que-2015-seja-anopromissor-para-crescimento-economico-do-rio-2015-01-05

Comisión Económica para América Latina y el Caribe (Cepal) (1951). Estudio Económico para América Latina 1949. Elaborado por la Secretaría de la Comisión Económica para América Latina [E/CN.12/164/Rev.1]. Nueva York: Naciones Unidas, Departamento de Asuntos Económicos. https://repositorio.cepal.org/bitstream/handle/11362/1003/1949_ es.pdf

Comissáo Econômica para a América Latina e o Caribe (Cepal) (2015). Bases de dados e publicaçôes estatística (Cepalstat). http://comtrade.un.org/.

Costa, A. M. de A. (2018). O processo de expropriação das terras do Açu e a trajetória de luta dos camponeses impactados pelo Projeto Minas-Rio. (Tese de Doutorado). Universidade do Estado do Rio de Janeiro (UerJ), Faculdade de Serviço Social (Fss), Rio de Janeiro, RJ.

Cruz, J. L. V. (2016). Dinâmica socioeconômica e territorial no estado do Rio de Janeiro contemporâneo. S. Gerschman \& A. M. S. P. Santos (orgs.), Saúde e politicas sociais no Rio de Janeiro (pp. 23-62). Rio de Janeiro: Fiocruz.

Cruz, J. L. V. \& Terra, D. (2015). Indústria extrativa petrolífera fluminense e limites ao desenvolvimento regional. Seminário Internacional sobre Desenvolvimento Regional, Santa Cruz do Sul, Rs, Brasil, 7.

Federação das Indústrias do Estado do Rio de Janeiro (FIRJAN). (2012). Decisão Rio 20122014. Rio de Janeiro: FirJan. file://C:/Users/User/Downloads/Decisao\%20Rio\%20 2012-2014.pdf

Ferchen, M. (2011). As relaçóes entre China e América Latina: impactos de curta ou longa duraçáa? Revista de Sociologia e Política, 19 (supl. 1), 105-130. http://dx.doi. org/10.1590/S0104-44782011000400008

Filgueiras, L. (2006). O neoliberalismo no Brasil: estrutura, dinâmica e ajuste do modelo econômico. Em E. M. Basualdo \& E. Acero, Neoliberalismo y sectores dominantes. Tendencias globales y experiências regionales. Buenos Aires: Consejo Latinoamericano de Ciencias Sociales (CLACSo). http://bibliotecavirtual.clacso.org.ar/ar/libros/grupos/ basua/C05Filgueiras.pdf

Gobetti, S. W. (2011). Federalismo fiscal e petróleo no Brasil e no mundo. Texto para discussão, n. ${ }^{\circ}$ 1669. Rio de Janeiro: Instituto de Pesquisa Económica Aplicada (IPEA). http:// repositorio.ipea.gov.br/bitstream/11058/1163/1/td_1669.pdf .

Gonçalves, R. (2012). Reduçáo das desigualdades de renda no governo Lula: análise comparativa. Em E. Salvador, E. Behring, I. Boschetti, \& S. Granemann, Financeirizaçâo, Fundo Público e Politica Social (pp. 13-30). São Paulo: Cortez. 
Gonçalves, R. (2014). O direito à cidade: o caso da favela Margem da Linha, em Campos dos Goytacazes. Rio de Janeiro: Mimeo.

Instituto Brasileiro de Geografia e Estatística (IBGE) (2015). Arranjos Populacionais e Concentraçôes Urbanas do Brasil. Rio de Janeiro: IBGE (2a ed., 2016. https://biblioteca. ibge.gov.br/visualizacao/livros/liv99700.pdf). https:/www.ibge.gov.br/apps/arranjos_ populacionais/2015/pdf/publicacao.pdf

Lazzarini, S. (2011). Capitalismo de laços: os donos do Brasil e suas conexóes. Rio de Janeiro: Elsevier.

Ministério da Infraestrutura, Brasil. (2011). Plano Nacional de Logística e Transportes. http:// infraestrutura.gov.br/conteudo/2814-pnlt-plano-nacional-de-logistica-e-transportes. html.

Monié, F. \& Vidal, S. (2006). Cidades, portos e cidades portuárias na era da integração produtiva. Revista de Administração Pública, 40(6), 975-995. http://www.scielo.br/ $\mathrm{pdf} / \% 0 \mathrm{D} / \mathrm{rap} / \mathrm{v} 40 \mathrm{n} 6 / 03 . \mathrm{pdf}$

Nolan, P. \& Zhang, J. (2010). Global competition after the financial crisis. New Left Review (64), 7-8 (July-Aug), 97-108.

Núcleo amigos da terra/Brasil (NAT). (2006). IIRSA: desvendando interesses. www.natbrasil.org.br.

Oliveira, F. J. G. (2008). Reestruturação produtiva, território e poder no Rio de Janeiro. Rio de Janeiro: Garamond.

Pedlowski, M. A. (2013). When the State becomes the land grabber: violence and dispossession in the name of 'development' in Brazil. Journal of Latin American Geography, 12(3), 91-111. http://muse.jhu.edu/journals/lag/summary/v012/12.3.pedlowski.html.

Pessanha, R. M. (2015). Canal da Nicarágua é parte do gigantismo naval e portuário e interfere no sistema portuário e no desenvolvimento brasileiro. http://www.robertomoraes.com. br/2015/05/canal-da-nicaragua-e-parte-do.html.

Pessanha, R. M. (2017). A relação transescalar e multidimensional "Petróleo-Porto" como produtora de novas territorialidades (Tese de Doutorado). Universidade do Estado do Rio de Janeiro (UerJ), Programa de Políticas Públicas e Formação Humana (PPFH), Rio de Janeiro, RJ, Brasil.

Pessanha, R. M. (2019). A “indústria” dos fundos financeiros: potências, estratégias e mobilidade no capitalismo contemporâneo. Rio de Janeiro: Consequência.

Petrobrás. (2014) Relatório final do diagnóstico participativo do PEA-BC: Referente ao Plano de Trabalho para continuidade do Diagnóstico Participativo da Bacia de Campos-PEA-BC:. http://pea-bc.ibp.org.br/arquivos/secoes/60_relatorio_pea_bc_rev.04_final.pdf

Piquet, R. (2007). Indústria do petróleo e dinâmica regional: reflexôes teórico-metodológicas. Em R. Piquet, \& R. Serra (orgs.), Petróleo e Regiāo no Brasil (pp. 15-33). Rio de Janeiro: Garamond.

Pikety, T. (2014). O capital no século XXI. Rio de Janeiro: Intrínseca.

Sader, E. \& Gentili, P. (orgs.) (1995). Pós-neoliberalismo: as politicas sociais e o estado democrático. São Paulo: Paz e Terra.

Sampaio Júnior, P. de A. (2012). Desenvolvimentismo e neodesenvolvimentismo: tragédia e farsa. Serviço Social \& Sociedade, (112), 672-688. http://dx.doi.org/10.1590/S010166282012000400004 .

Souza, J., Terra, D., \& Campos, M. (2015). Mobilidade populacional e as novas espacialidades urbanas: municípios da Ompetro. EURE, 41(123), 53-80. http://dx.doi.org/10.4067/ S0250-7161201500030000 